\title{
Power Efficient GaN HEMT High Power Amplifier Design Operating at 5-7GHz Bandwidth
}

\author{
Syed Mudassir Hussain, Talha Mir, Mehr Gul, Atiq ur Rehman, \\ Zahid Rauf, Rahila Umer, Jan Muhammad
}

Faculty of Information \& Communication Technology, BUITEMS.

\begin{abstract}
For the next generation applications in the mobile, radar and satellite communication we need the devices that can operate at high frequencies and high power with minimum power consumption. There is a growing importance in the recent years for the development of gallium Nitride (GaN) transistors. This paper presents design of the power efficient GaN based high power amplifier operating in the bandwidth of $5 \mathrm{GHz}-7 \mathrm{GHz}$ based on a 12 Watt Discrete Power GaN on SiC HEMT from TriQuint. In this manuscript the design of radio frequency (RF) power amplifier, its stability, input and output matching impedance and performance for 5-7GHz is presented. Design and simulations of the power amplifier are carried out using advanced design system (ADS). Simulation results of device stability, gain and power added efficiency (PAE) shows good accordance with the specifications and parameters of the device. In the design process, for better correlation in measurement and simulation results precision of passive element models are specially considered. In $1 \mathrm{~dB}$ compression point for the designed high power amplifier, the experiment and the simulation results show a power efficiency of $68 \%$.
\end{abstract}

Keywords-High power amplifier, power added efficiency, GaN HEMT

Date Received 19-10-2020

Date Accepted 28-10-2020

Date Published 18-12-2020

\section{INTRODUCTION}

$\mathrm{H}$ IGH power amplifier (HPA) plays a very vital role in many communication system designs specially the mobile and wireless communication. Particularly the application specific amplifier designs, where the features like high gain of the amplifier, improved efficiency wide bandwidth, reliability, high output power, and good thermal performance are required only the novel transistor technologies can meet such stringent performances.

High electron mobility transistors (HEMTs) with a large breakdown voltages can meet the requirements of wide band wireless and mobile applications. Advancements in the diversity of these devices like SiC MESFET, Gallium Arsenide (GaAs), and Gallium Nitride HEMTs are considered appropriate for such applications $[1,2]$. GaN based transistors can provide far superior performance compared to its counterpart like Gallium Arsenide (GaAs), and hence are of great concern to the technologists.

The HPA has an extensive technical and economic prominence because of a substantial outlays, in the production of RF equipment. Devices for instance, mobile phones and PDAs, HPA consumes most of the power. Both in base station equipment infrastructure and portable devices, the HPA has to placate numerous stringent requirements. In many 4G, 5G, marine, airborne radar systems and military applications where the DC power is limited and inadequate which needs a highly efficient HPA designs. Most of the currently existing HPAs are being operated at narrow bandwidths.

\section{A. Prior Works}

Gallium Arsenide (GaAs) and Gallium Nitride $(\mathrm{GaN})$ are competing for the future power devices and microwave applications, however due to material properties GaN based devices have more abilities to operate at high temperatures and high voltages than GaAs. Huet et al [3], presented the design of GaAs pHEMT power amplifier providing the maximum power added efficiency (PAE) of $45 \%$ operating over a bandwidth from 8-12 GHz. Chu et al [4] demonstrated the peak output power of $12.6 \mathrm{~W}$ with peak PAE $52.6 \%$ at $9.4 \mathrm{GHz}$. Communication systems like radar and mobile requires an output power levels of more than 20W [5]. The GaN based power amplifiers have provided a better power added efficiency than its counterpart for example Silicon ( $\mathrm{Si}$ ) and Gallium Arsenide (GaAs) and at the frequency range 1-12 GHz.

Costrini et al [6], presented a design of X-band power amplifier in micro-strip $\mathrm{AlGaN} / \mathrm{GaN}$ technology, with the biasing operating point $20 \mathrm{~V}$ provided power added efficiency (PAE) $30-40 \%$ over the bandwidth from $8-10.5 \mathrm{GHz}$. In another 
research work. [7], wide band GaN HEMT power amplifier was designed operating over $1-3 \mathrm{GHz}$ bandwidth, with the drain bias point set to $28 \mathrm{~V}$ the output power was measured to be at 41.43dBm (14W) and PAE $68.27 \%$.

To make HPAs suitable for modern communication systems with wide band operating frequencies at the same time offering high power added efficiency a careful design adaptations are required [11, 12, and 14]. A better power added efficiency (PAE) of high power amplifier for wide band applications is a potential area of research for the next generation communication systems $(4 \mathrm{G} / 5 \mathrm{G})$. The major challenges in designing a power amplifier is the trade off in output power and power added efficiency as well as to design an amplifier which can operate over wide bandwidth [13]. To achieve high power added efficiency the selection of the appropriate device is the most important task.

In this work, to achieve a high output power efficiency 12 W GaN based HEMT on SiC from TriQuint (TGF2023-2-02) has been used. It is a large signal model developed by TriQuint the key specifications of the device meet our requirements as we wanted to produce power efficiency more than $58 \%$ to use it for wide band frequency applications. In this design we chose the RF frequency range of $5-7 \mathrm{GHz}$ with the center frequency of $6 \mathrm{GHz}$.

\section{Methodology}

Key steps to be followed in design phase of the power amplifier are as follows: DC and Load line analysis:

1. Bias and Stability

2. Load Pull Analysis

3. Impedance Matching

4. PA Final Characterization

5. Optimize/Fine Tune the design

\section{A. Bias-Network}

This network is used to transmit current and the desired voltage to the amplifier. It should have a high impedance so that it may not overload the core transmission line. In the presented work this type of transmission lines have a single frequency at which it behaves like a high impedance that is $6 \mathrm{GHz}$. The main reason of using a bias network is to block all harmonic components [8].

\section{B. Stability factor}

Another imperative parameter in case of high power amplifier design is its stability, and it is very essential that the amplifier should be stable for the whole bandwidth available, without the stability factor amplifier behaves like an oscillating circuit. The stability design of amplifier is a key part of the amplifier and it can be calculated as follows [9]:
$K=\frac{1-\left|S_{11}\right|-\left|S_{22}\right|+\left|S_{11} \cdot S_{22}-S_{12} \cdot S_{21}\right|^{2}}{2 .\left|S_{11}\right| \cdot\left|S_{22}\right|}>1$

Equation (1) shows $K>1$, this condition can be determined through S-parameters in ADS [10]. For the analysis and to understand the behavior of the RF device operating a particular frequency band S-parameters are calculated.

\section{EXPERIMENTAL RESULTS}

\section{A. Device selection}

Figure 1 shows the schematic of GaN HEMT parameter simulation to check its stability and the Figure 2 shows the simulation results of parameters S21 and S1 1 above $20 \mathrm{~dB}$ and below $0 \mathrm{~dB}$ respectively where the $\mathrm{S} 11$ parameter shows the

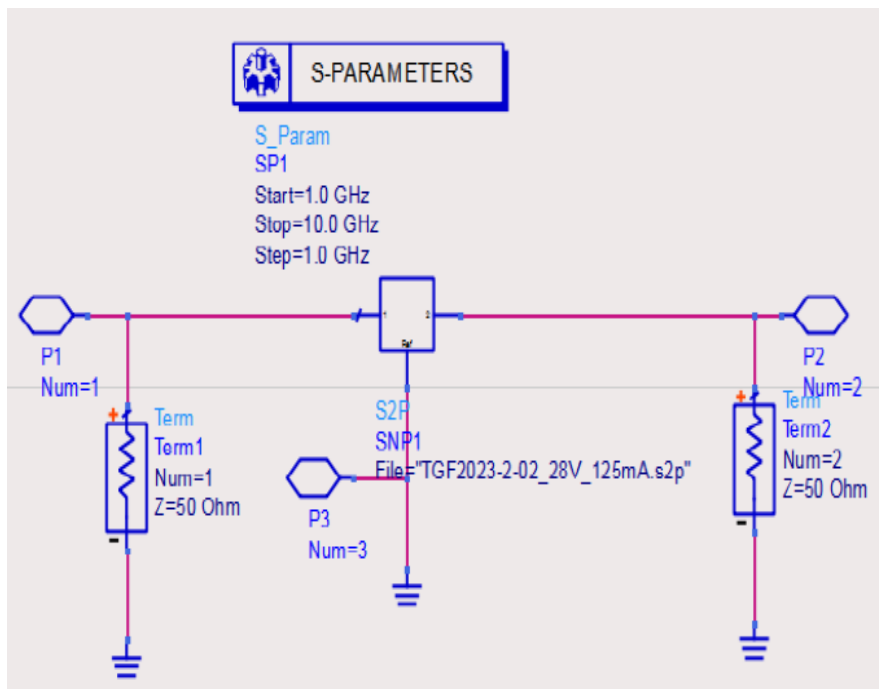

Fig. 1. Selected GaN HEMT parameters simulation

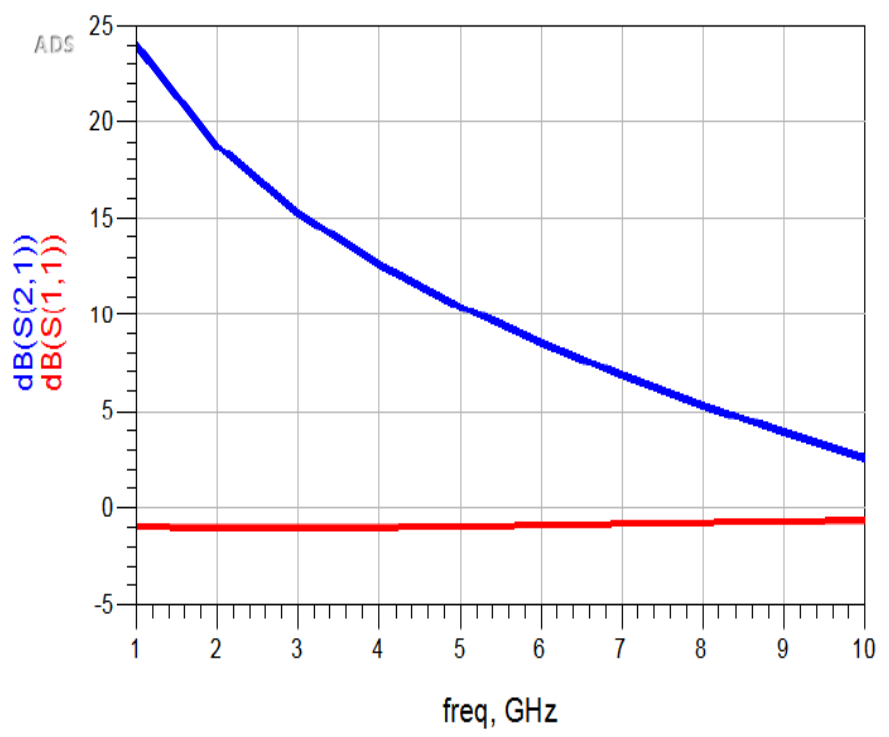

Fig. 2. Selected GaN HEMT parameters simulation graph for S21 and S11

signal reflected back at port 1 and S21 shows the signal exiting at port 2 for the incident signal at port 1 . 


\section{B. Bias Network Design}

Bias circuit is realized on microstrip substrate, the parameters are shown in Table 1. Physical and substrate parameters are obtained from the LineCal tool for the bias circuit at the center frequency of $6 \mathrm{GHz}$.

TABLE I

Substrate and Physical Parameters

\begin{tabular}{|c|c|c|c|c|c|}
\hline \hline \multicolumn{4}{|c|}{ Parameters of the Substrate } & \multicolumn{2}{|c|}{$\begin{array}{c}\text { Physical } \\
\text { Dimensions }\end{array}$} \\
\hline$\varepsilon_{\mathrm{r}}$ & $\begin{array}{c}\text { Relative } \\
\text { permeability } \\
\text { Mur }\end{array}$ & $\begin{array}{c}\text { Substrate } \\
\text { thickness } \\
(\mathrm{H})\end{array}$ & $\begin{array}{c}\text { Conductor } \\
\text { thickness } \\
(\mathrm{T})\end{array}$ & $\mathrm{W}$ & $\mathrm{L}$ \\
\hline 5.15 & 1 & $0.640 \mathrm{~mm}$ & $17.5 \mathrm{um}$ & $1.06 \mathrm{~mm}$ & $4.88 \mathrm{~mm}$ \\
\hline \hline
\end{tabular}

\section{Drain Bias Network}

Using the stripe line geometry the drain biasing network is shown in the Figure 3 and its simulation results for S21 and S11 are shown in Figure 4 and 5 respectively. Figure 4 shows the value of S21 of the sub circuit (drain bias) for the amplifier with the frequency range of $4-8 \mathrm{GHz}$, it can be seen that the value of S21 is near to zero for the whole band, however in this design the band of interest is from 5-7GHZ. In case of drain biasing and gate biasing S21 should be as low as possible.

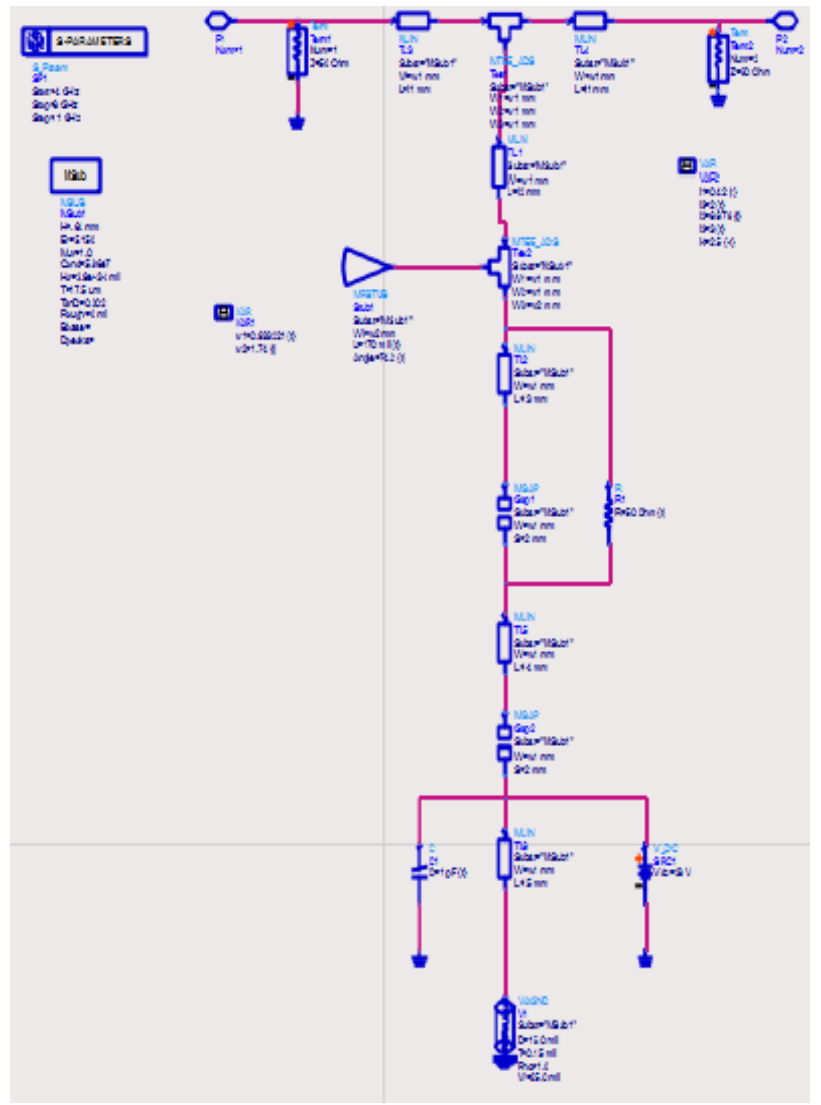

Fig. 3. Drain bias network for GaN HEMT power device

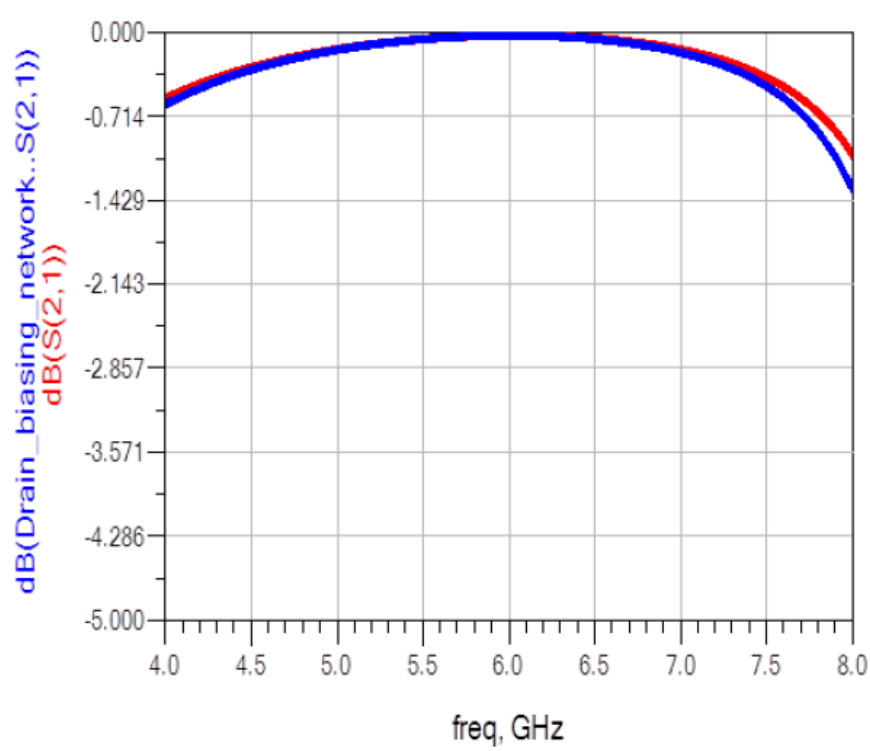

Fig. 4. Simulation result of Drain Bias (Sub circuit) for S21

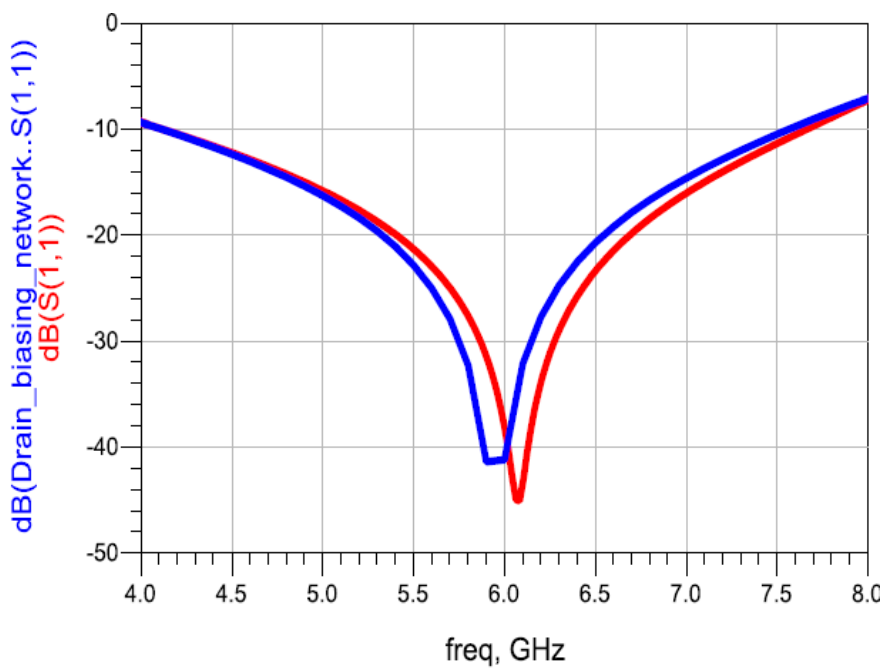

Fig.5. Simulation result of Drain Bias (Sub circuit) for S11

S11 refers to the signal reflected at Port 1 for the signal incident at Port 1. For the stable amplifier the value of S11 should be less than -10dB. Figure 5 shows the output of S11 for the drain bias circuit. It can been seen that the output is less than $-10 \mathrm{~dB}$ for the band of interest $(5-7 \mathrm{GHz})$ and at $6 \mathrm{GHz}$ center frequency the output is less than $-40 \mathrm{~dB}$.

\section{Gate biasing Network}

After the drain biasing, the next step for the amplifier is to calculate the S-parameters S21 and S11 for its gate biased network, Figure 6 and 7 shows the simulations of gate biasing network. Figure 6 shows the output of the sub circuit (gate bias), it can be seen that the $\mathrm{S} 21=-0.0421 \mathrm{~dB}$ at center frequency $6 \mathrm{GHz}$ near to zero. The Figure 7 shows the output of gate bias network for S11 again the output found to be less than $-10 \mathrm{~dB}$ for the whole band of interest $(5 \mathrm{GHz}-7 \mathrm{GHz})$. Results obtained from the drain and gate biasing networks depicts the performance of device is stable for the whole band and can be used for small signal analysis of designed amplifier. 


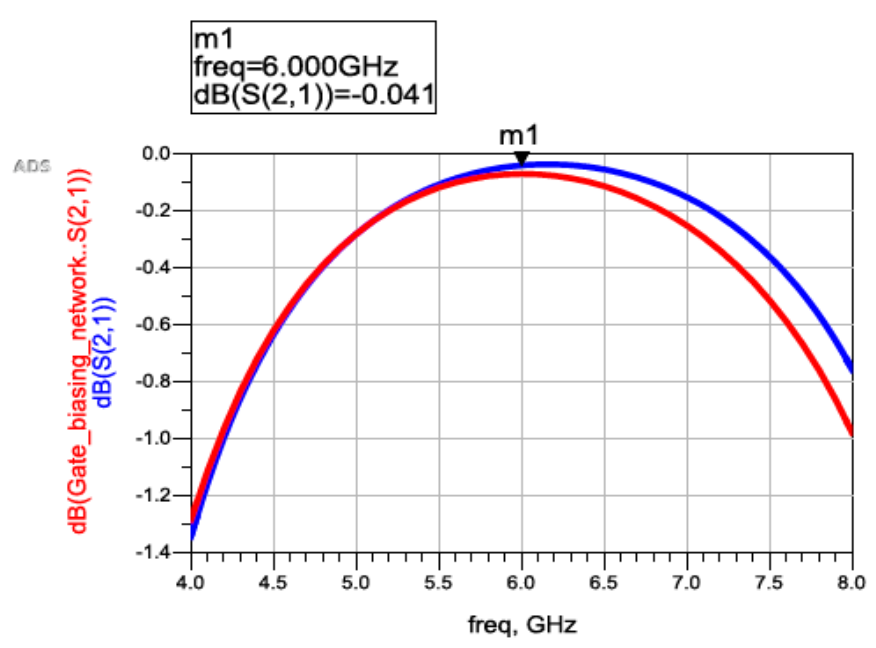

Fig. 6. Simulation result of Gate Bias (Sub circuit) for S21

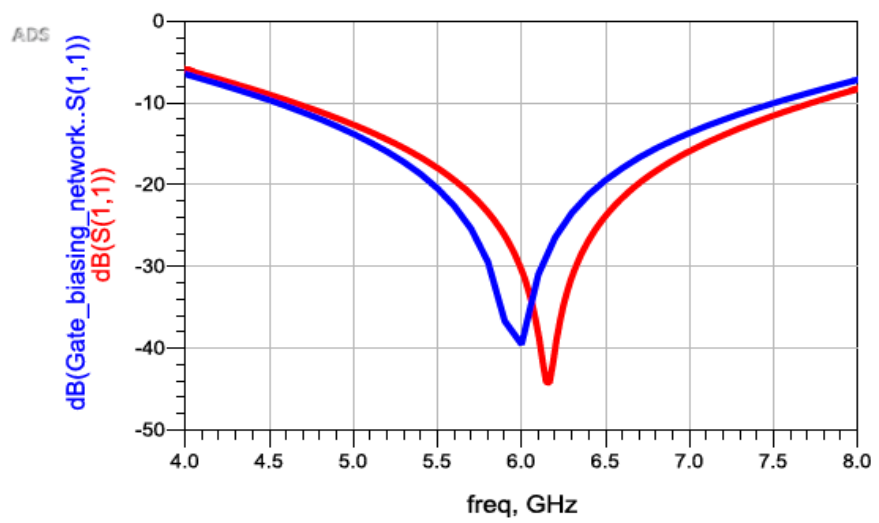

Fig.7. Simulation result of Gate Bias (Sub circuit) for S11

\section{E. Small Signal Stability Analysis}

To ensure the proper functionality of the designed amplifier and its passive components, the small signal stability analysis and its optimization is required. If the amplifier is not properly biased it may produce the non-linear output. After completing the biasing networks of drain and the gate the small signal

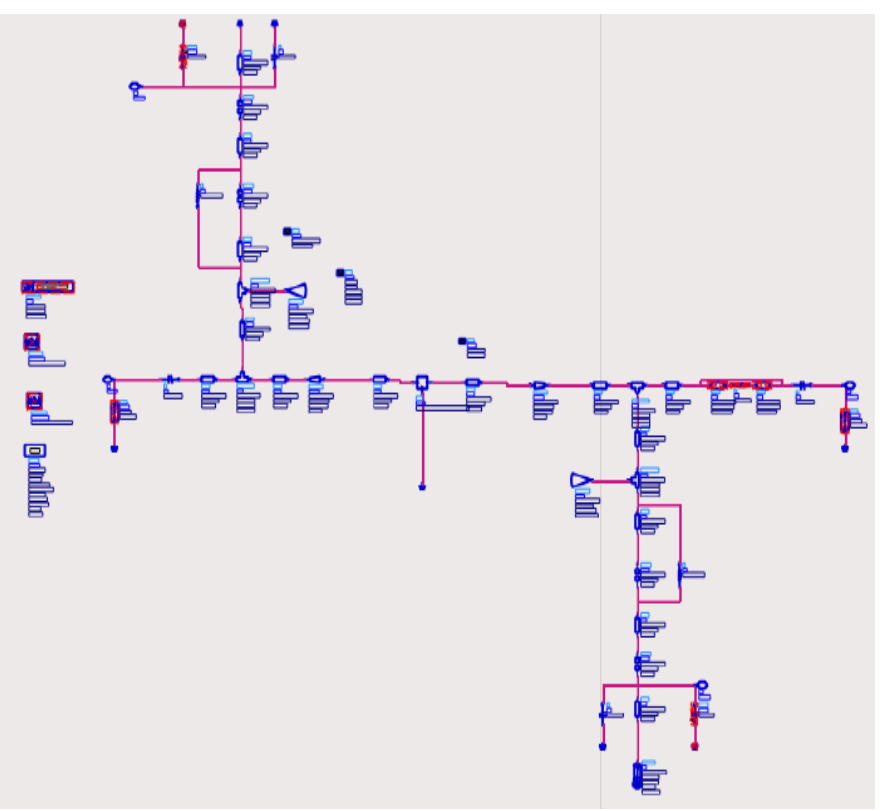

analysis for the device is done. The schematic of the design is shown in Figure 8. The small signal stability analysis and small signal gain (S21) simulation results are shown in the Figure 9 and Figure 10 respectively.

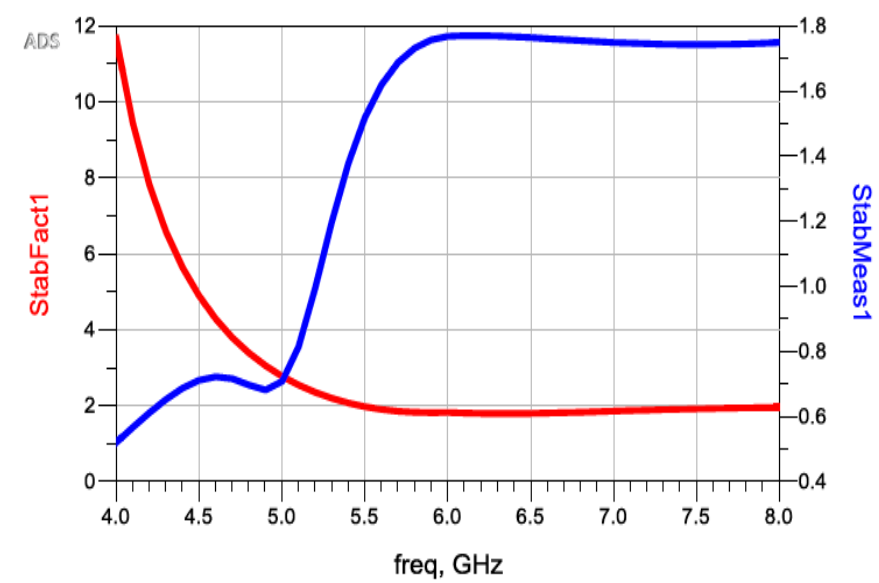

Fig. 9. Small signal Stability factor graph

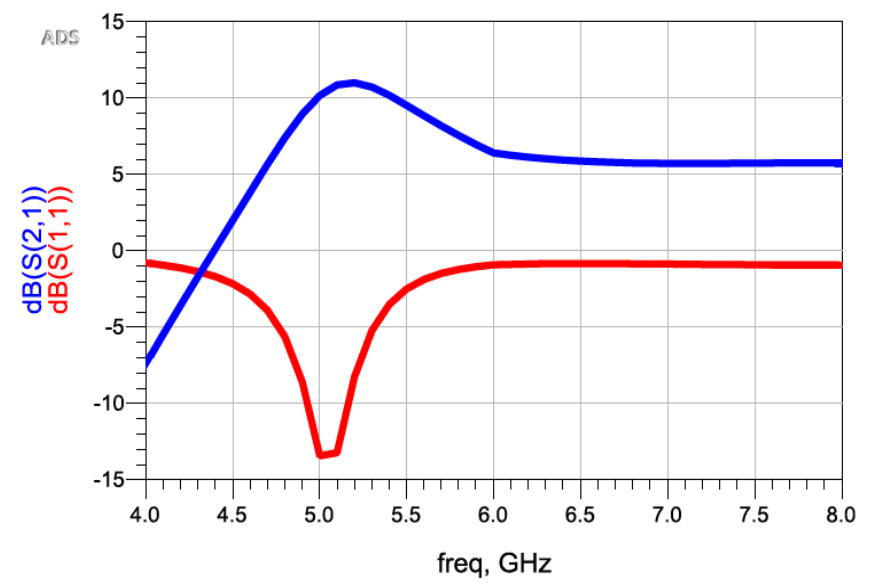

Fig. 10. small signal gain (S21) and S11

Figure 9 depicts the stability of the amplifier for its small signal analysis, as it is already discussed in equation (1) section II, the stability factor $K$ should be greater than $1(K>1)$. In Figure 9 it can be seen that the stability factor $K$ is greater than 1 for the whole band of interest i.e. $5-7 \mathrm{GHz}$, which means that the circuit is stable for the entire band. In the given graph, stability factor is plotted on the left-Y axis with liner scale and stability measure is plotted on the right- $\mathrm{Y}$ axis and the $\mathrm{X}$-axis shows the frequency range. The Figure 10 shows the small signal gain (S21) greater than $10 \mathrm{~dB}$ at $5 \mathrm{GHz}$ and the $\mathrm{S} 11$ less than $-10 \mathrm{~dB}$ at $5 \mathrm{GHz}$.

\section{F. Large signal measurements}

Figure 11, depicts the simulation result for the given input power on the $\mathrm{X}$-axis with the corresponding power added efficiency on the $\mathrm{Y}$-axis for the operating frequency band of 57GHz. For every frequency component the input power is variable. Because in the operating bandwidth the driver circuit cannot provide similar power to the whole bandwidth. Power added efficiency is measured to be around $68 \%$ at $6 \mathrm{GHz}$ and the input power is $33 \mathrm{dBm}$.

Fig.8. Schematic for small signal analysis 


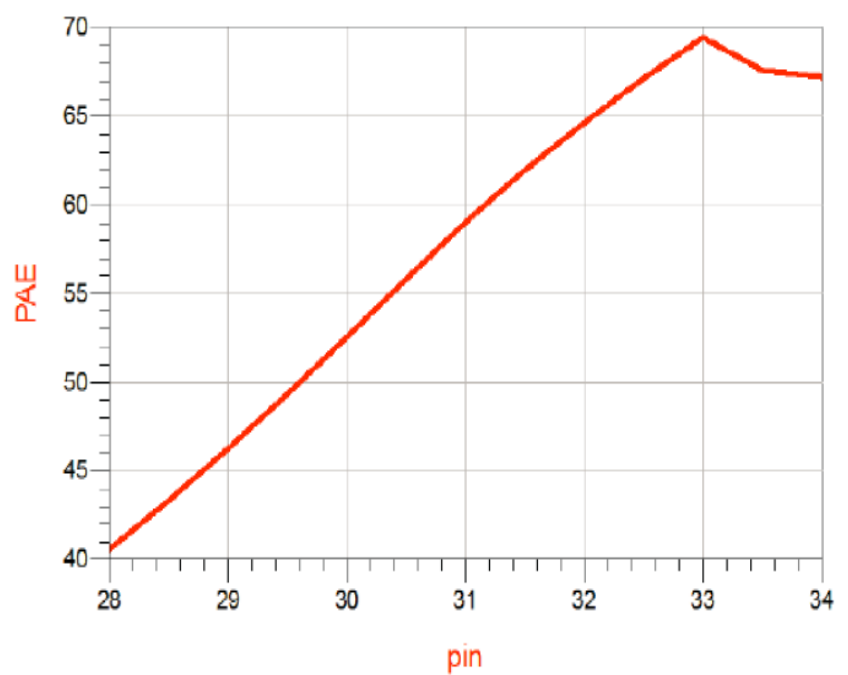

Fig.11. Power added efficiency versus input power

TABLE II

Summary of Results

\begin{tabular}{|c|c|c|}
\hline \hline Objectives & $\begin{array}{c}\text { Results of this } \\
\text { work }\end{array}$ & $\begin{array}{c}\text { Results of Work } \\
\text { done [7] }\end{array}$ \\
\hline Device & $\begin{array}{c}12 \mathrm{~W} \mathrm{GaN} \mathrm{Based} \\
\text { HEMT on SiC } \\
\text { from TriQuint } \\
\text { (TGF2023-2-02) }\end{array}$ & $\begin{array}{c}\text { 10 W GaN power } \\
\text { amplifier from } \\
\text { Cree } \\
\text { (CGH40010F) }\end{array}$ \\
\hline Bandwidth & $\begin{array}{c}5 \mathrm{GHz}-7 \mathrm{GHz} \\
\text { center frequency } \\
6 \mathrm{GHz}\end{array}$ & $\begin{array}{c}1 \mathrm{GHz}-3 \mathrm{GHz} \\
\text { center frequency } \\
2 \mathrm{GHz}\end{array}$ \\
\hline Amplifier type & Class AB & Class AB \\
\hline Operation & $28 \mathrm{~V}-32 \mathrm{~V}$ & $28 \mathrm{~V}$ \\
\hline PAE & $68 \%($ at $6 \mathrm{GHz})$ & $68.27 \%$ at $2 \mathrm{GHz})$ \\
\hline Stability & Stable for the & Stable for the \\
whole band & whole band \\
\hline \hline
\end{tabular}

\section{CONCLUSIONS}

Power amplifiers are considered to be the most important part of any communication system and transmitter/receiver modules. The major challenges in designing a power amplifier is the trade off in output power and power added efficiency as well as to design an amplifier which can operate over wide bandwidth. For this purpose, $12 \mathrm{~W} \mathrm{GaN}$ based HEMT on SiC from TriQuint (TGF2023-2-02) has been used. In this paper we chose the RF frequency range of $5-7 \mathrm{GHz}$ with the center frequency of $6 \mathrm{GHz}$ and calculated power added efficiency of $68 \%$. The results obtained are compared with the already work done on $10 \mathrm{~W} \mathrm{GaN}$ based power amplifiers. A comparison of results is given in the following table in terms of operating frequency the design is found to be stable for whole band.

\section{REFERENCES}

[1] U.K. Mishra, P. Parikh, and Y.F. Wu. "AlGaN/GaN HEMTs An overview of device Operation and applications", 2002.

[2] GaN overview. [Online]. Last accessed 2019 http: //www.gainmicrowave.com/gallium_nitride_overview.php

[3] T. Huet , J. Gruenenpuett , Z. Ouarch , D. Bouw , V. Serru , M. Camiade, C. Chang and P. Chaumas "A $8 \mathrm{~W}$ high efficiency Xband power pHEMT amplifier", Proc. 38th Eur. Microw. Conf., pp.289-292 2008.

[4] C.-K. Chu , H.-K. Huang , H.-Z. Liu , C.-H. Lin , C.-H. Chang, C.-L. Wu ,C.-S. Chang and Y.-H. Wang "An X-band high-power and high-PAE PHEMT MMIC power amplifier for pulse and CW operation", IEEE Microw. Wireless Compon. Lett., vol. 18, no. 10, pp.707 -709 2008.

[5] J. Dutta "AlGaN/GaN-HEMT Power Amplifiers with Optimized Power-Added Efficiency for X-Band Applications" PhD dissertation, 2011.

[6] M. Calori, A. Cetronio, C. Lanzieri, S. Lavanga, M. Peroni, E. Limiti, A. Serino, G C. Costrini. Ghione, and G. Melone, "A 20 Watt Microstrip X-Band AlGaN/GaN HPA MMIC for Advanced Radar Applications," in Proceedings of the 3rd European Microwave Integrated Circuits Conference, EuMIC 2008, Amsterdam, Netherlands, , pp. 566 - 569. Oct. 2008.

[7] M.H. Yilmaz, "Design of a wide band $10 \mathrm{~W}$ GaN Power amplifier", Master dissertation, 2011.

[8] R. K. Joshi and A. R. Harish. Characteristics of a rotated butterfly stub. IEEE MIT-S International Microwave Sysmposium, San Francisco, USA, 2006.

[9] X. Luo, C. Vue, L. Zhou, W. Yu and X. Lv, Design of a Ka-band GaN HEMT Power Amplifier Based on Simulation, International Workshop on Microwave and Millimeter Wave Circuits and System Technology, 2013.

[10] Agilent Technologies. Guide to Harmonic Balance Simulation in ADS. Advanced Design System Product Documentation. 2009.

[11] H. C. Jeong, H.Seok, Ahmed, K.W. Yeom "Design of X-band 40 W Pulse-Driven GaN HEMT power amplifier", Microwave Conference Proceedings (APMC), 2012 Asia-Pacific, On page(s): 466 - 468. 2012.

[12] S. Piotrowicz, E. Morvan, R. Aubry, S. Bansropun, T. Bouvet,E. Chartier, T. Dean, O. Drisse, C. Dua, D. Floriot, M. di-Forte Poisson, Y. Gourdel, A. Hydesa, J. Jacquet, O. Jardel,D. Lancereau, J. M. Lean, G. Lecoustre, A. Martin, Z. Ouarch,T. Reveyrand, M. Richard, N. Sarazin, D. Thenot, and S. Delage, "State of the Art 58W, 38\% PAE X-Band AlGaN/GaN HEMTs Microstrip MMIC Amplifiers," in IEEE Compound Semiconductor Integrated Circuit Symposium Digest, , pp. 1 - 4. 2008.

[13] C. Bowick. RF Circuit Design. Newnes, inc., 2008.

[14] S. C. Cripps. RF Power Amplifiers for Wireless Communications. Artech House, inc., 2006.

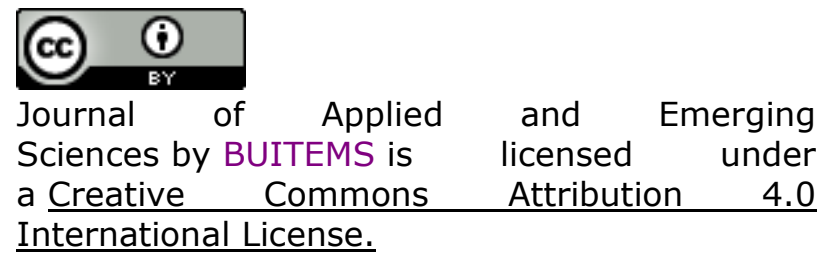

